\title{
Effects of oestradiol benzoate treatment on the reproductive performance and endocrine status of sows after lactations of 10 or 35 days
}

\author{
R. N. Kirkwood, ${ }^{*}$, K. R. Lapwood $\dagger$, W. C. Smith*, K. Moller $\ddagger$ \\ and D. J. Garrick*
}

Departments of *Animal Science, $\uparrow$ Physiology and Anatomy and $\ddagger$ Veterinary Clinical Sciences, Massey University, Palmerston North, New Zealand

\begin{abstract}
Summary. Forty-two Landrace $\times$ Large White sows were used in 3 studies of oestradiol benzoate treatment $24 \mathrm{~h}(\mathrm{E} 1)$ or $48 \mathrm{~h}(\mathrm{E} 2)$ after piglet removal, following lactations of $10(\mathrm{~S})$ or $35(\mathrm{~L})$ days, or were untreated controls (C). For Exp. 1, oestradiol benzoate doses were 4,16 and $64 \mu \mathrm{g} / \mathrm{kg}$ body weight; since highest mean $\mathrm{LH}$ peaks followed use of the $16 \mu \mathrm{g} / \mathrm{kg}$ dose, this treatment was used in later studies. Treatments for Exp. 2 were $S-E 1$ and $L-E 1(N=3)$. Pregnancy rates were $1 / 3$ and $2 / 3$, respectively, while 10 day weaned sows tended to have longer weaning-remating intervals, shorter oestrous periods and lower post-injection oestradiol peaks. Post-treatment LH peaks were recorded from all L-E1 sows, but only one S-E1 animal. Treatments S-E2, L-E2, S-C and L-C $(\mathrm{N}=6)$ were used in Exp. 3; pregnancy rates were $1 / 6,6 / 6,5 / 6$ and $6 / 6$, respectively, while peak oestradiol levels were $49 \cdot 5 \pm 8 \cdot 3,74 \cdot 8 \pm 15 \cdot 1,21 \cdot 7 \pm 2 \cdot 0$ and $51.8 \pm 26.5 \mathrm{pg} / \mathrm{ml}$, respectively. Weaning-remating intervals were extended in S-C sows $(P<0.05)$, while oestradiol treatment prolonged behavioural oestrus. LH peak values were reduced after short lactations, but not affected by oestradiol treatment. Plasma prolactin concentrations at weaning were higher in sows in treatment $S$ than in treatment $\mathrm{L}$, while at the subsequent oestrus in oestradiol-treated sows they were elevated more and for longer periods than in controls. These results demonstrate that reduced gonadotrophin secretion and fertility after short lactations are not overcome by treatment with oestradiol benzoate.
\end{abstract}

\section{Introduction}

Weaning of piglets after short lactations is associated with reduced subsequent reproductive performance in sows. While ovulation rate is unaffected by lactation length, short lactations result in an increase in the weaning to remating intervals and in early embryonic mortality (Varley \& Cole, 1976). The cause of this reduced performance remains to be determined, although recent interest has focussed on the post-weaning endocrine status of the sow.

The inhibitory influences controlling lactational anoestrus lessen as lactation proceeds (Elsaesser \& Parvizi, 1980; Kirkwood, Lapwood, Smith \& Anderson, 1984) and there is rapid recovery in hypothalamic stores of gonadotrophin-releasing hormone $(\mathrm{GnRH})$ after weaning (Cox \& Britt, 1982a). Further, short lactations have been shown to be associated with reduced gonadotrophin secretion at the first post-weaning oestrus (Edwards \& Foxcroft, 1983; Kirkwood et al., 1984). The reasons for this reduction of gonadotrophin secretion and its physiological consequences are not known. It has been suggested that the hypothalamus of the sow may be less responsive to oestrogen stimulation at the post-weaning oestrus after short lactations (Kirkwood $e t$ al., 1984). However, previous studies using oestrogen to control sow reproduction used high dose 
levels, with consequent non-physiological plasma oestrogen profiles (Elsaesser \& Parvizi, 1980; Edwards \& Foxcroft, 1983).

This study was undertaken to determine a minimum effective dose of oestradiol benzoate for induction of oestrus and thereafter to ascertain the influence of this dose on plasma $\mathrm{LH}$ and prolactin concentrations in sows after very short lactations. The influences of oestrogen therapy on the weaning to remating interval, duration of the oestrous period and subsequent pregnancy rates were noted.

\section{Materials and Methods}

\section{Animals and treatments}

Between November 1982 and August 1983, 42 multiparous Landrace $\times$ Large White sows, weighing $165-250 \mathrm{~kg}$, were used in 3 studies of induction of oestrus with oestradiol benzoate (oestradiol benzoate in ethyl oleate: Intervet, Artarmon, NSW, Australia). After lactations of 35 (L) or 10 (S) days sows were transferred to individual stalls in a room without temperature or photoperiod control and fed $2 \mathrm{~kg}$ daily of a standard sow breeding diet. Oestrogen treatments were made by injection of oestradiol benzoate into the neck muscles at $08: 00 \mathrm{~h}$, either $24 \mathrm{~h}(\mathrm{E} 1)$ or $48 \mathrm{~h}$ (E1) after piglet removal. Control animals (C) did not receive oestrogen. Treatment combinations of lactation length and oestradiol were therefore designated S-E1, L-E1, S-E2, L-E2, S-C and L-C.

Experiment 1. Sows were randomly allocated for treatment after 35-day lactations using oestradiol benzoate doses of 4,16 or $64 \mu \mathrm{g} / \mathrm{kg}$ body weight $(\mathrm{N}=4$ in each). Oestrogen was administered $24 \mathrm{~h}$ after weaning and blood samples were taken directly from an ear vein at 12-h intervals for $72 \mathrm{~h}$ from the time of injection. Sows were tested daily for onset of oestrus with boar contact at $07: 00$ and 17:00 $\mathrm{h}$ and mated on the first 2 days of oestrus. Duration of oestrus was not determined in these animals.

Experiment 2. Immediately after weaning sows in Groups S-E1 and L-E1 (N $=3$ in each) were fitted with vinyl (Dural Plastics and Engineering, Dural, NSW, Australia) vena caval cannulae via a prominent ear vein, whilst restrained without anaesthetic. Oestradiol benzoate was administered at $16 \mu \mathrm{g} / \mathrm{kg}$ body weight. Blood samples were taken at the time of weaning $(08: 00 \mathrm{~h}$, Day 0), and thereafter at 8-h intervals $(06: 00,14: 00$ and $22: 00 \mathrm{~h})$ until $72 \mathrm{~h}$ after the first mating. Oestrus was detected by boar contact at the same times as in Exp. 1, daily from 2 days after weaning until the end of oestrus or 5 days after the first mating. If a sow still stood for the boar at the end of testing, the oestrous period was given a value of $120 \mathrm{~h}$. From first standing for the boar, service was allowed for 3 consecutive days.

Experiment 3. Since abnormal oestrous behaviour and low pregnancy rates were recorded in Exp. 2, oestrogen therapy was delayed until $48 \mathrm{~h}$ after weaning and the treatment groups were therefore S-E2, L-E2, S-C and L-C (N = 6 in each). Oestradiol dose, blood sampling and detection of oestrus were as for Exp. 2. Additionally, a blood sample was taken 5 days after mating for progesterone assay, as an indicator of luteal status.

For all experiments, blood samples were collected into heparinized tubes, centrifuged and the plasma stored at $-20^{\circ} \mathrm{C}$ until assayed.

\section{Hormone assays}

$L H$. Samples from each experiment were assayed for LH concentration by the method of Niswender, Reichert \& Zimmerman (1970), which has been previously validated in this laboratory (FlorCruz \& Lapwood, 1978). The assay utilized rabbit anti-porcine LH serum (pool No. 566, courtesy of Dr G. D. Niswender), porcine LH (LER 788/4, courtesy of Dr L. E. Reichert) for assay standards and highly purified porcine LH (LER 786/3, courtesy of Dr L. E. Reichert) for 
radioiodination. Mean assay sensitivity, defined as the minimum hormone concentration significantly different from zero (Burger, Lee \& Rennie, 1972), was $0 \cdot 14 \mathrm{ng} / \mathrm{ml}(n=3)$. Intra-assay coefficients of variation (CV) were 13.0 and $12.0 \%$ and inter-assay CVs were 11.9 and $6.1 \%$, for plasma samples having mean LH concentrations of 1.27 and $2.14 \mathrm{ng} / \mathrm{ml}$, respectively.

Prolactin. Plasma prolactin concentrations for samples from Exps 2 and 3 were determined by the method of van Landeghem \& van de Wiel (1978) which has been validated in this laboratory (Kirwood et al., 1984). This assay utilized rabbit anti-ovine prolactin serum which is highly specific for porcine prolactin (courtesy of Dr D. F. M. van de Wiel), porcine prolactin (AEW-SP-162C prepared by Dr A. E. Wilhelmi and donated by Dr L. E. Reichert) for assay standards and highly purified porcine prolactin (LER-2073, courtesy of Dr L. E. Reichert) for radioiodination. Mean assay sensitivity was $0.20 \mathrm{ng} / \mathrm{ml}(n=3)$. Intra-assay CVs were $7 \cdot 0,7 \cdot 3$ and $9 \cdot 3 \%$ and inter-assay CVs were $6 \cdot 1,4 \cdot 1$ and $5 \cdot 0 \%$ for plasma samples containing mean prolactin concentrations of $35 \cdot 8$, $22 \cdot 1$ and $5 \cdot 8 \mathrm{ng} / \mathrm{ml}$, respectively.

Oestradiol $-17 \beta$. Determinations were made on the first sample collected each day during Exps 2 and 3, by the method of Smith, Drost, Fairclough, Peterson \& Tervitt (1976). This assay has been validated for pig plasma (Kirkwood et al., 1984). Mean assay sensitivity was $10 \mathrm{pg} / \mathrm{ml}(n=4)$. Intra-assay CVs were 10.8 and $11.6 \%$ and inter-assay CVs were 11.0 and $6.0 \%$ for plasma samples containing mean oestradiol- $17 \beta$ concentrations of 42.8 and $135.8 \mathrm{pg} / \mathrm{ml}$, respectively.

Progesterone. The method of Kirkwood et al. (1984) was used for plasma samples from Exp. 3 that were collected 5 days after first mating. All samples were processed in a single assay. Assay sensitivity was $0.05 \mathrm{ng} / \mathrm{ml}$ while intra-assay CVs were $9.3,11.8$ and $11.4 \%$ for plasma samples containing mean progesterone concentrations of $1 \cdot 1,5 \cdot 8$ and $9 \cdot 3 \mathrm{ng} / \mathrm{ml}$, respectively.

\section{Statistical analyses}

Data pertaining to weaning to remating intervals and durations of oestrus were subjected to analysis of variance and differences between means tested for significance using Tukey's test (Snedecor \& Cochran, 1974). Hormone profiles were constructed for plasma LH and prolactin data for the first 3 days after weaning and from 1 day before to 2 days after the peak. Oestradiol profiles were constructed for the period from 2 days before until 3 days after peak oestradiol values were recorded. All such profiles were then analysed for treatment effects using a repeated measure multivariate profile analysis (Morrison, 1976).

\section{Results}

\section{Experiment I}

Oestradiol benzoate treatment $24 \mathrm{~h}$ after weaning, at doses of 4,16 or $64 \mu \mathrm{g} / \mathrm{kg}$ body weight, induced $\mathrm{LH}$ peaks of $4.88 \pm 1.34,7.80 \pm 1.95$ and $4.34 \pm 0.68 \mathrm{ng} / \mathrm{ml}$, respectively. All sows, except one in the $4 \mu \mathrm{g} / \mathrm{kg}$ group, also displayed behavioural oestrus.

\section{Experiment 2}

All sows displayed behavioural oestrus. The mean \pm s.e.m. weaning to remating intervals, durations of oestrus and pregnancy rates, for sows in Groups S-El and L-El were: $4 \cdot 0 \pm 0.0$ and $3 \cdot 2 \pm 0 \cdot 2$ days, $88 \cdot 0 \pm 17 \cdot 5$ and $104 \cdot 0 \pm 8 \cdot 0 \mathrm{~h}$, and $1 / 3$ and $2 / 3$, respectively. Peak oestradiol levels (Text-fig. 1) for Groups S-E1 and L-E1 were $45 \cdot 3 \pm 5 \cdot 7$ and $64 \cdot 3 \pm 4 \cdot 3 \mathrm{pg} / \mathrm{ml}$ respectively, and were attained $24 \mathrm{~h}$ after injection. These levels had fallen to $18 \cdot \overline{3} \pm 8 \cdot 8$ and $30 \cdot 7 \pm 9 \cdot 4 \mathrm{pg} / \mathrm{ml}$, respectively, $48 \mathrm{~h}$ later. 


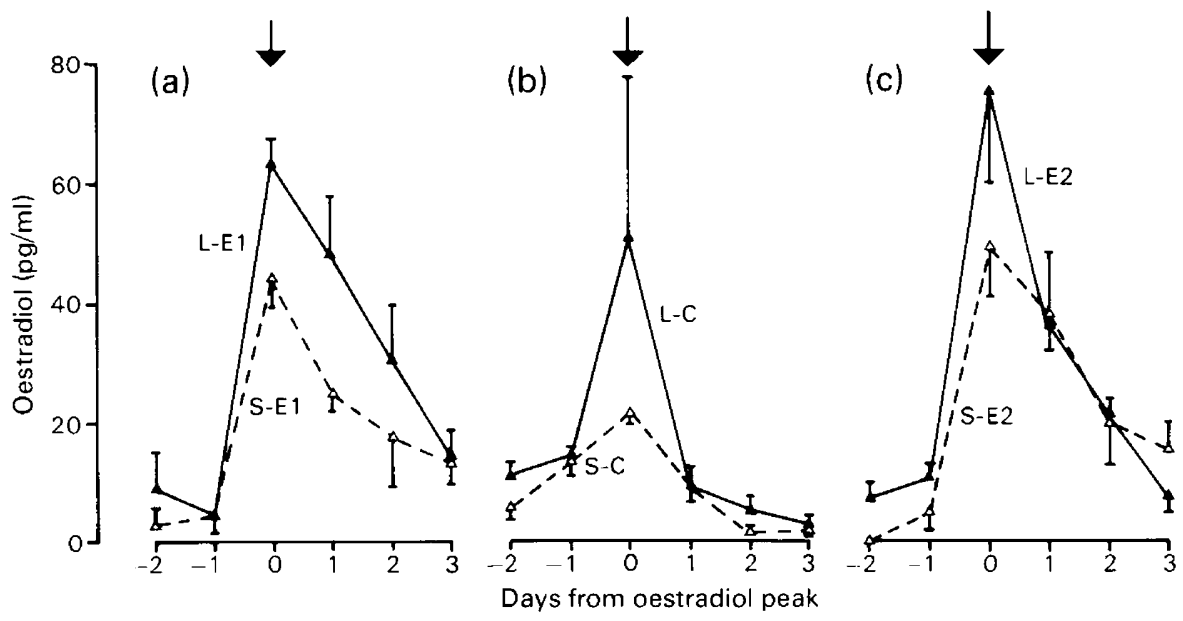

Text-fig. 1. Mean + s.e.m. plasma oestradiol- $17 \beta$ concentrations recorded from (a) oestradioltreated sows in Exp. 2, (b) control sows in Exp. 3, and (c) oestradiol-treated sows in Exp. 3, after lactation for $10(\Delta \cdots \Delta)$ or $35(\Delta-\Delta)$ days. Times of peak oestradiol levels are indicated with arrows.

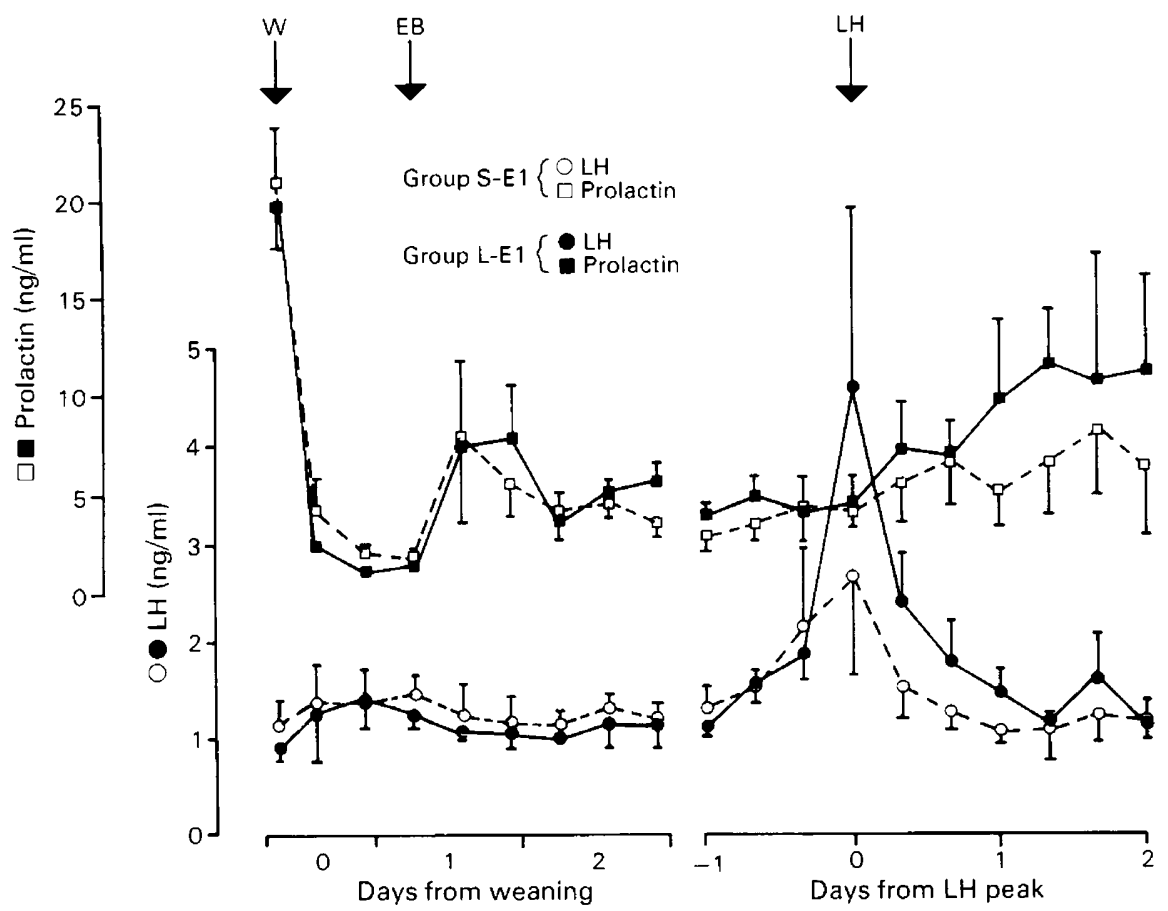

Text-fig. 2. Mean \pm s.e.m. plasma LH and prolactin concentrations recorded from sows in Exp. 2, during the first 3 days after weaning and from $24 \mathrm{~h}$ before until $48 \mathrm{~h}$ after the ovulatory LH peak. Times of weaning (W), oestradiol injection (EB) and LH peak (LH) are indicated with arrows.

There were no significant effects of weaning regimen on daily mean plasma LH levels (Text-fig. 2) during the first 3 days after weaning. All sows in Group L-E1 displayed LH peaks $48-72 \mathrm{~h}$ after oestradiol injection; mean \pm s.e.m. height of these peaks was $4.5 \pm 1.86 \mathrm{ng} / \mathrm{ml}$. Only one sow in Group S-El had an LH peak, of $4.63 \mathrm{ng} / \mathrm{ml}$, which occurred $96 \mathrm{~h}$ after injection. At weaning mean 
plasma prolactin levels (Text-fig. 2) for sows in Groups S-E1 and L-E1 were $20.92 \pm 2.32$ and $19.52 \pm 2.05 \mathrm{ng} / \mathrm{ml}$, respectively, but by $6 \mathrm{~h}$ after weaning concentrations had fallen to $4.16 \pm 1.56$ and $2 . \overline{46} \pm 0.29 \mathrm{ng} / \mathrm{ml}$. Mean daily plasma prolactin content was significantly $(P<0.05)$ elevated on the day of oestrogen injection (Day 1) with highest levels of $8.66 \pm 3.21$ and $9.12 \pm 3.53 \mathrm{ng} / \mathrm{ml}$, being achieved in Groups S-E1 and L-E1, respectively, $8 \mathrm{~h}$ after injection. Post-weaning daily mean prolactin levels on Day 2, while lower than on Day 1, were still higher $(P<0.05)$ than on Day 0 . Plasma prolactin concentrations for both groups peaked again at the time of oestrus, but profiles were not influenced significantly by weaning regimen.

\section{Experiment 3}

All sows displayed behavioural oestrus. Results for weaning to remating intervals, durations of oestrus, times from oestradiol injection to LH peak and pregnancy rates are given in Table 1.

The only significant difference in weaning to remating intervals was that it was longer for sows in Group S-C $(P<0.05)$ compared with the other 3 groups. Within weaning regimen, exogenous oestradiol prolonged the duration of oestrus $(P<0.05)$, which was also longer for Group S-E2 than for Group L-E2 $(P<0.05)$. Plasma oestradiol levels (Text-fig. 1) peaked $24 \mathrm{~h}$ after oestradiol treatment; peak values were higher and concentrations remained elevated for longer $(P<0.05)$ in Groups S-E2 and L-E2 than in Groups S-C and L-C.

Analysis of LH profiles (Text-fig. 3) for the first 3 days after weaning indicated no influence of weaning regimen or oestradiol treatment. However, there was a significant effect of weaning regimen on preovulatory peak $\mathrm{LH}$ levels, overall mean values $(5.67 \pm 0.67$ compared with $3 \cdot 16 \pm$ $0.31 \mathrm{ng} / \mathrm{ml}$, respectively, $P<0.02$ ) being higher in Groups L-E2 and $\mathrm{L}-\mathrm{C}$ than in Groups S-E2 and $\mathrm{S}-\mathrm{C}$. Within weaning regimen, $\mathrm{LH}$ peaks tended to be lower for sows in Groups S-E2 and L-E2 $(3.91 \pm 0.45 \mathrm{ng} / \mathrm{ml})$ than in Groups L-C and S-C $(4.91 \pm 0.77 \mathrm{ng} / \mathrm{ml})$, although the difference was not statistically significant.

Plasma prolactin levels (Text-fig. 3) at the time of weaning were significantly higher in sows in Groups S-E2 and S-C than in Groups L-E2 and L-C (36.99 \pm 3.32 compared with 17.86 \pm 2.32 $\mathrm{ng} / \mathrm{ml}, P<0.001$ ), but in all sows had reached levels of $<5 \mathrm{ng} / \mathrm{ml}$ within $6 \mathrm{~h}$ of weaning. Starting from $6 \mathrm{~h}$ after weaning, the weaning regimen had no significant influence on daily mean plasma levels of prolactin on post-weaning Days 0,1 or 2 . However, the oestradiol treatment $\times$ day interaction showed that daily mean prolactin levels achieved in sows in Groups S-E2 and L-E2 on Day 2 were higher $(P<0.01)$ than in those in Groups S-C and L-C. The importance of that effect must be interpreted with caution because values for the oestradiol-treated sows were already higher than those for control sows on Day 1, i.e. before the oestradiol injection. At the time of oestrus there was no influence of weaning regimen on prolactin levels, but levels were elevated more and for a longer period $(P<0.02)$ in Groups S-E2 and L-E2 than in Groups S-C and L-C.

Table 1. Effects of oestradiol benzoate on reproductive performance and timing of LH peaks in sows in Exp. 3

\begin{tabular}{|c|c|c|c|c|}
\hline & \multicolumn{4}{|c|}{ Treatment } \\
\hline & Group S-E2 & Group L-E2 & Group S-C & Group L-C \\
\hline Remating interval (days) & $4 \cdot 4 \pm 0 \cdot 2$ & $4 \cdot 0 \pm 0 \cdot 1$ & $5 \cdot 8 \pm 0.5$ & $4 \cdot 6 \pm 0 \cdot 3$ \\
\hline Duration of oestrus (h) & $110 \cdot 0 \pm 10 \cdot 0$ & $72 \cdot 0 \pm 8 \cdot 1$ & $54 \cdot 0 \pm 4 \cdot 1$ & $40 \cdot 0 \pm 4 \cdot 0$ \\
\hline \multicolumn{5}{|l|}{$\begin{array}{l}\text { Interval from oestradiol } \\
\text { injection to LH } \\
\text { peak (h) }\end{array}$} \\
\hline peak (h) & $62 \cdot 7 \pm 4 \cdot 81$ & $44 \cdot 0 \pm 2 \cdot 73$ & - & - \\
\hline Pregnancy rate & $1 / 6$ & $6 / 6$ & $5 / 6$ & $6 / 6$ \\
\hline
\end{tabular}


R. N. Kirkwood et al.
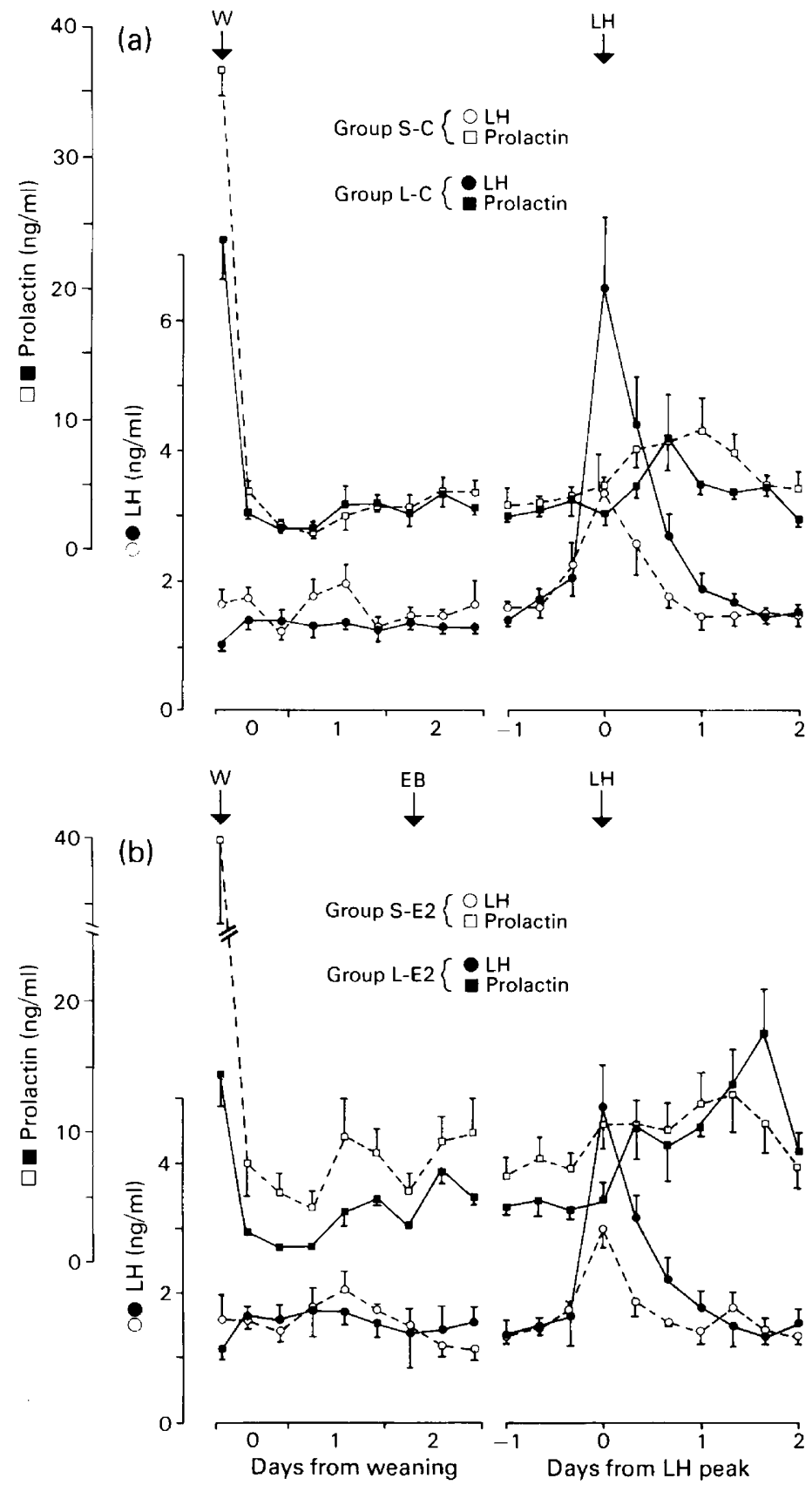

Text-fig. 3. Mean \pm s.e.m. plasma $\mathrm{LH}$ and prolactin concentrations recorded from (a) control and (b) oestradiol-treated sows in Exp. 3, during the first 3 days after weaning, and from $24 \mathrm{~h}$ before until $48 \mathrm{~h}$ after the ovulatory LH peak. Times of weaning (W), oestradiol injection (EB) and $\mathrm{LH}$ peak $(\mathrm{LH})$ are indicated with arrows.

Progesterone assay of plasma samples taken 5 days after first mating showed elevated levels in all sows in Groups L-E2, L-C and S-C (overall mean value $10.5 \pm 1.5 \mathrm{ng} / \mathrm{ml}$ ). Of the sows in Group $\mathrm{S}-\mathrm{E} 2$, one conceived and had a plasma progesterone level of $6.6 \mathrm{ng} / \mathrm{ml}$. One of the remaining 5 sows had a progesterone level of $3.3 \mathrm{ng} / \mathrm{ml}$, while all others had levels of $<1.0 \mathrm{ng} / \mathrm{ml}$. 


\section{Discussion}

The principal aim of the experiments described in this paper was to develop an oestradiol benzoate treatment regimen for induction of fertile oestrus in sows, especially after short lactations. At a dose of $16 \mu \mathrm{g} / \mathrm{kg}$ body weight, oestradiol benzoate induced maximal height LH peaks in Exp. 1. In Exps 2 and 3 that dose also was followed by plasma oestradiol peaks that were in height and duration, within the upper part of the physiological range which has been recorded for untreated sows, after lactation for 35 days, as measured with the present oestradiol assay (Kirkwood et al., 1984; Group L-C, Exp. 3).

The efficacy of $16 \mu \mathrm{g}$ oestradiol benzoate $/ \mathrm{kg}$ body weight for induction of oestrus could not be assessed in the present studies because all animals in Exps 2 and 3, including untreated controls, displayed behavioural oestrus. While consideration of the $\mathrm{LH}$ response data indicated that higher oestradiol benzoate doses may be required, particularly after short lactations, Hausler et al. (1980) concluded that low pregnancy rates after treatment with PMSG-hCG at 5 or 10 days post partum were due to decreased ovarian responsiveness and/or an unfavourable uterine environment. Also, prolonged high plasma levels of oestrogen have been shown to prevent the periovulatory rise in plasma FSH concentrations (Edwards \& Foxcroft, 1983) and high post-mating oestrogen concentrations may adversely affect tubal egg transport, with consequently increased embryo mortality (Varley, Atkinson \& Ross, 1981). Such factors may have contributed to the reduction in pregnancy rates of sows in Group S-E2 compared with that of sows in Group S-C in Exp. 3. Increasing the dose of oestradiol would almost certainly have exacerbated the potential management problems associated with the prolonged intense behavioural oestrus which followed oestradiol benzoate treatment in these studies.

Clearly the timing of oestrogen administration is important. When given $24 \mathrm{~h}$ after weaning an LH response was observed in sows which had lactated for 5 weeks (Group L-E1), while 2 of 3 sows in Group S-E1, failed to show such an LH peak. It is therefore evident that at this time the hypothalamic/pituitary unit is relatively insensitive to oestrogen stimulation. This would appear to be due to the short period between parturition and weaning, rather than to the timing of oestradiol application in relation to weaning, since a normal $\mathrm{LH}$ response can be elicited in response to GnRH treatment later in lactation (Bevers, Willemse, Kruip \& van de Wiel, 1981; Cox \& Britt, 1982b) and also in response to oestrogen given $24 \mathrm{~h}$ after weaning to sows after a 5-week lactation (Exp. 2; Edwards \& Foxcroft, 1983). The occurrence of LH peaks in sows in Group S-E2 suggests that, even after very short lactations, the hypothalamic/pituitary unit recovers very rapidly. However, as noted here and in previous work (Edwards \& Foxcroft, 1983; Kirkwood et al., 1984), short lactations are associated with a reduced output of $\mathbf{L H}$ at the first post-weaning oestrus. The administration of oestrogen failed to increase the gonadotrophic response in sows in Groups S-E2 and L-E2, or in the studies of Edwards \& Foxcroft (1983). Indeed, the LH peaks in these groups tended to be smaller (not significant) than in the corresponding control groups. The question of whether this gonadotrophin insufficiency was due to lower pituitary LH levels, or to reduced hypothalamic/pituitary responsiveness, remains unanswered. The evidence from the present work favours the latter possibility, because the time lapse between oestrogen injection and LH peak was significantly longer in sows in Group S-E2 than in those in Group L-E2.

Low levels of progesterone observed in 5 of 6 sows in Group S-E2 indicate that the ovary is not responsive immediately after weaning after very short lactations. The reasons for this remain to be determined, although an inhibitory influence of exogenous oestrogen on follicular development has been noted when given to sows $24 \mathrm{~h}$ after weaning, even after lactations of 5 weeks (Edwards \& Foxcroft, 1983). The present results indicate that after short lactations this inhibitory influence may still be evident when oestrogen is given $48 \mathrm{~h}$ after weaning.

Plasma prolactin concentrations were significantly higher in the sows after weaning at 10 than at 35 days. Since no effect of stage of lactation on plasma prolactin has been noted in previous work (Kirkwood et al., 1984), these data probably reflect the increased probability of sows with young 
litters having had a recent suckling episode. Exogenous oestrogen rapidly elevated plasma prolactin, although levels fell within $24 \mathrm{~h}$ of oestrogen injection. It is therefore difficult to explain the significant effect of prior oestrogen therapy on prolactin levels at oestrus. A temporal relationship between high prolactin levels and behavioural oestrus has been documented (van de Wiel, Erkens, Koops, Vos \& van Landeghem, 1981), but the functional significance of that relationship is not known. All sows treated with oestradiol benzoate in this study had high, prolonged periovulatory plasma prolactin levels, and experienced prolonged and intense behavioural oestrus, even though plasma oestradiol fell to low levels within 48-72 h of injection.

In conclusion, these studies indicate that the prolonged weaning to remating intervals of sows after very short lactations may be attributable to a reduced response of the hypothalamic/pituitary unit to oestrogen stimulation, although recovery of response was rapid. Additionally, although not measured directly in these studies, the results indicate that ovarian responsiveness to gonadotrophic stimulation is low in the early post-weaning period after short lactations. Finally, the results of this and other work (Edwards \& Foxcroft, 1983) indicate that the use of oestrogen to control sow reproduction may be limited to therapeutic situations, such as when sows have a prolonged anoestrous period after weaning.

We thank Dr D. F. M. van de Wiel, Research Institute for Animal Husbandry, Zeist, The Netherlands; Dr G. D. Niswender, Colorado State University, CO, U.S.A.; Dr L. E. Reichert, Jr, Albany Medical College, Albany, NY, U.S.A. and Dr J. T. France, National Women's Hospital, Auckland, New Zealand, for radioimmunoassay materials; Dr A. J. Peterson, Ruakura Agricultural Research Station, Hamilton, New Zealand, for supplying the materials and facilities for the oestradiol-17 $\beta$ radioimmunoassay; Mr H. J. Elgar and Miss R. R. Shanley for their expert technical assistance; and Mr K. Best, for care of the experimental animals.

\section{References}

Bevers, M.M., Willemse, A.H., Kruip, Th.A.M. \& van de Wiel, D.F.M. (1981) Prolactin levels and the LH response to synthetic LH-RH in the lactating sow. Anim. Reprod. Sci. 4, 155-163.

Burger, H.S., Lee, V.W.K. \& Rennie, G.C. (1972) A generalised computer programme for the treatment of data from competitive protein-binding assays including radioimmunoassays. J. Lab. clin. Med. $\mathbf{8 0}$, $302-312$.

Cox, N.M. \& Britt, J.H. (1982a) Relationship between exogenous gonadotropin-releasing hormone, gonadotropins and follicular development after weaning in sows. Biol. Reprod. 27, 70-78.

Cox, N.M. \& Britt, J.H. (1982b) Pulsatile administration of gonadotropin-releasing hormone to lactating sows: endocrine changes associated with induction of fertile estrus. Biol. Reprod. 27, 1126-1137.

Edwards, S. \& Foxcroft, G.R. (1983) Response of sows to oestradiol benzoate treatment after weaning at two stages of lactation. J. Reprod. Fert. 67, 173-180.

EIsaesser, F. \& Parvizi, N. (1980) Partial recovery of the stimulatory oestrogen feedback action on $\mathrm{LH}$ release during late lactation in the pig. J. Reprod. Fert. 59, 63-67.

FlorCruz, S.V. \& Lapwood, K.R. (1978) A longitudinal study of pubertal development in boars. Int. J. Androl. 1, 317-330.

Hausler, C.L., Hodson, H.H., Kuo, D.C., Kinney, T.J., Rauwolf, V.A. \& Strack, L.E. (1980) Induced ovula- tion and conception in lactating sows. J. Anim. Sci. 50, 773-778.

Kirkwood, R.N., Lapwood, K.R., Smith, W.C. \& Anderson, I.L. (1984) Plasma concentrations of LH, prolactin, oestradiol-17 $\beta$ and progesterone in sows weaned after lactation for 10 or 35 days. J. Reprod. Fert. 70, 95-102.

Morrison, D.F. (1976) Multivariate Statistical Methods, pp. 205-216. McGraw-Hill, New York.

Niswender, G.D., Reichert, L.E. \& Zimmerman, D.R. (1970) Radioimmunoassay of serum levels of luteinising hormone throughout the estrous cycle in pigs. Endocrinology 87, 576-580.

Smith, J.F., Drost, H., Fairclough, R.J., Peterson, A.J. \& Tervitt, H.R. (1976) Effect of age on peripheral levels of progesterone and oestradiol-17 $\beta$ and duration of oestrus in Romney Marsh ewes. N.Z. Jlagric. Res. 19, $277-280$.

Snedecor, G.W. \& Cochran, W.G. (1974) Statistical Methods, pp. 271-275. Iowa State University Press, Ames.

van de Wiel, D.F.M., Erkens, J., Koops, W., Vos, E. \& van Landeghem, A.A.J. (1981) Periestrous and midluteal time courses of circulating LH, FSH, prolactin, estradiol-17 $\beta$ and progesterone in the domestic pig. Biol. Reprod. 24, 223-233.

van Landeghem, A.A.J. \& van de Wiel, D.F.M. (1978) Radioimmunoassay for porcine prolactin: plasma levels during lactation, suckling and weaning and 
after TRH administration. Acta endocr., Copenh. 88, 653-668.

Varley, M.A. \& Cole, D.J.A. (1976) Studies in sow reproduction. 4. The effect of level of feeding in lactation and during the interval from weaning to remating on the subsequent reproductive performance of the early weaned sow. Anim. Prod. 22, 71-77.
Varley, M.A., Atkinson, T. \& Ross, N. (1981) The effect of lactation length on the circulating concentrations of progesterone and oestradiol in the early weaned sow. Theriogenology 16, 179-184.

Received 28 December 1983 